\title{
Post Leprosy-Elimination Era: Relevance of Research in Race Yet Unfinished
}

\section{Jadhav RS*}

Department of Microbiology, The Institute of Science, India

*Corresponding author: Jadhav RS, Department of Microbiology, The Institute of Science, 15, Madame Cama Road, Mumbai, India, 400032; Email: rupenjadhav@yahoo.com

\section{Opinion}

Volume 4 Issue 3

Received Date: May 12, 2020

Published Date: June 01, 2020

DOI: $10.23880 /$ eij-16000149

\section{Abstract}

Leprosy is one of the oldest known infectious diseases. Prevalence of the disease has significantly come down but the new case detection rate is not changing much. Elimination of the disease has been achieved by many countries Stigma associated with the disease is due to deformities it causes. Immunological biomarkers that can help in early preventive intervention are still elusive. Though multi drug therapy (MDT) is still very effective in treating the disease, the fear looms large of development of drug resistance. Moving forward towards eradication of the disease is still a challenge.

Keywords: Leprosy; Elimination; Eradication; Disability; Drug Resistance; Transmission

Abbreviations: SNP: Single Nucleotide Polymorphism; MLVA: Multi-Locus Variable Number of Tandem Repeats Analysis; NLEP: National Leprosy Eradication Programme of India.

\section{Introduction}

Extinction of any infectious disease can be achieved by public health interventions that require strategic planning. This planning involves consideration of transitions of disease through stages like disease control, elimination of disease, elimination of infection, eradication of the disease that ultimately will result in final extinction of the disease [1]. Leprosy is one of the oldest known infectious diseases. WHO strategy has helped to bring down the leprosy as a public health problem in many countries. The number of new cases reported globally during 2004 were 407791 whereas in 2018 it was 208641 showing a decline of $49 \%$ [2,3]. But if we look at the annual new case detection since 2004, it is apparent that the number of new cases detected globally as well as in India in last five years i.e. since 2014 is almost same. Out of 159 countries that provided data to WHO in 2018, three countries viz. India, Brazil and Indonesia reported more than
10000 new cases [3]. Moving from elimination of disease to elimination of infection will require focused approach.

\section{Discussion}

The status of leprosy in India as well as globally need to be assessed in the frame of stages that an infectious disease goes prior to its extinction so that we will be able to actually understand where we are. For eradication of infectious diseases it is important to have prophylactic measures like availability of vaccine or one need to know the source of infection and the reservoir of the infectious agent so that using appropriate intervention strategies, the interruption of disease transmission can be achieved. Unfortunately, for leprosy neither we have effective vaccine that could be used for prophylaxis of population nor we are very sure of all possible sources of infection. It is desirable to have focus in these areas.

India declared elimination of leprosy at national level in 2005. In last 15 years the disease should have slowly gone down. As Mycobacterium leprae, causative agent of leprosy is an obligate pathogen and human being as the only 
likely natural host (at least in subcontinent), diagnosis and treatment of the new cases should have yielded the expected results. This assumption is based on the fact that only active leprosy cases are likely to act as reservoir for the pathogen and treating active cases should probably suffice to bring down the bacterial load in the community and hence the transmission. In 2004, India reported 260063 new cases (against global case load of 343863) which declined to 169709 in 2005 [2]. This helped India to declare elimination of the disease at national level. This decline continued in 2006 as well where the new cases reported were 139252. Since then the number of new cases detected in India have fluctuated between 120000 to 135000 which contributes to almost $60 \%$ of the total global case load $[3,4]$. The data from weekly epidemiological records of WHO as well as the National Leprosy Eradication Programme of India (NLEP), the number of cases globally as well as in India have marginally declined in last 10 years (Figure 1 ).

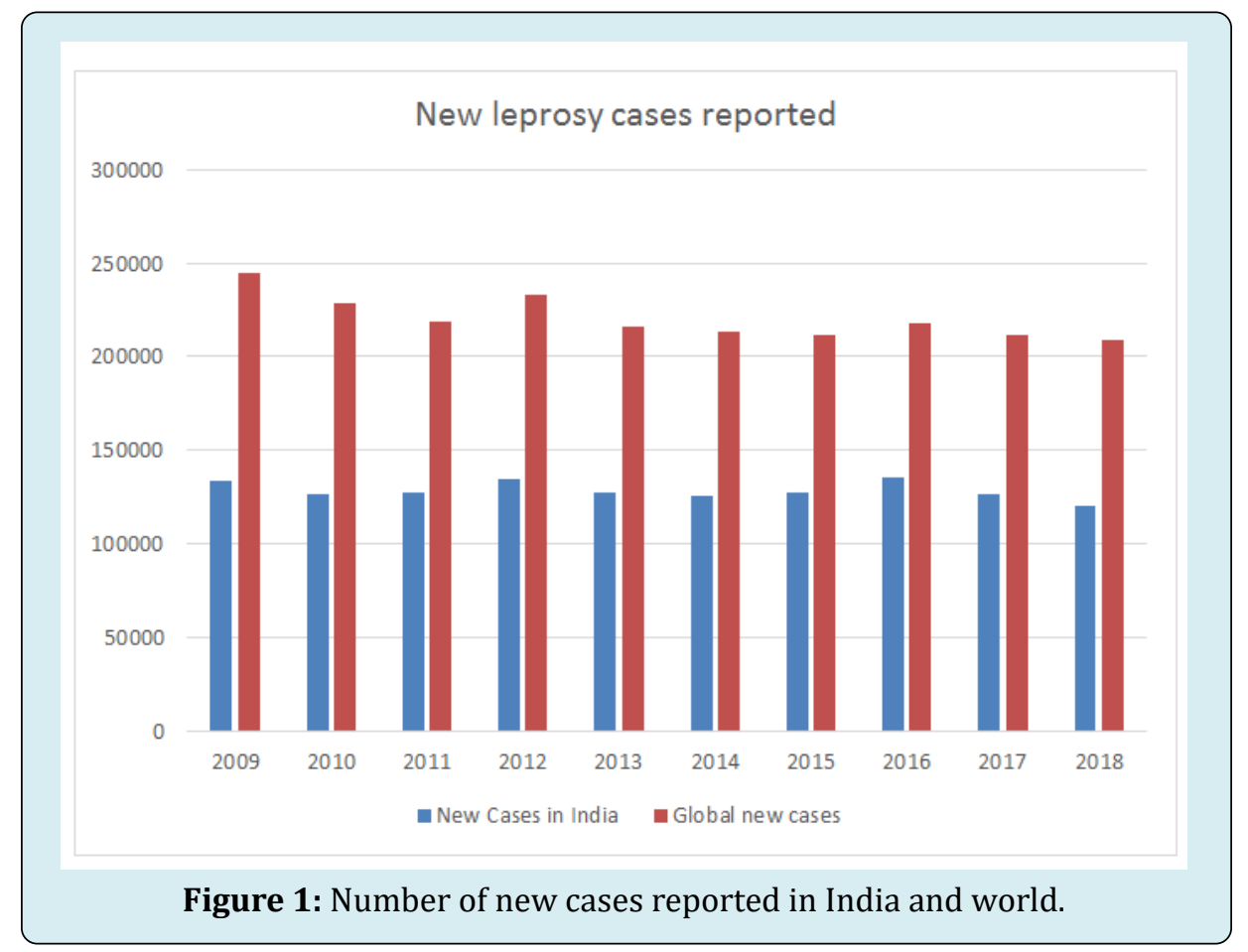

These observations raise questions about reservoir of infectious agent. When passive case reporting is relied upon for case detection then we will not be sure about the gap between reported number of cases and actual number of cases. As there is no regular active surveillance for case detection, the possibility of presence of unreported/hidden cases in the community can't be ruled out. National sample surveys can help us to find out the proportion of such hidden, unreported cases. Long incubation period of the disease and time lag between clinical manifestation of the disease and its diagnosis can have impact on the disease transmission in the community. Many reports have suggested sub-clinical infection in normal healthy population in endemic areas [57]. But it is still a challenge to discern difference between sub-clinical infection and transient carriage. Reports have also indicated possibility of extra-human reservoir for the pathogen [8-10]. Though M. leprae is obligate pathogen, possibility of its survival in the environment where higher life forms like amoebae acting as protective niche can't be ruled out [11-13]. This can further complicate transmission of the disease. Techniques like single nucleotide polymorphism (SNP) and multi-locus variable number of tandem repeats analysis (MLVA) can help us to trace transmission chain $[14,15]$.

Role of climate in survival of M. leprae in the environment, personal \& community hygiene, sanitation and exposure risks for the disease transmission are still areas that require more clarity. It is a known fact that in developed countries leprosy disappeared with economic development. One can assume that economic development was linked with better sanitation, improved hygiene, supply of treated and piped water, mechanisation of farming practices, literacy etc. Link of this with decreased disease transmission appears logical and needs further investigation. High endemic pockets of leprosy need to be evaluated for transmission with reference sanitation, hygiene, illiteracy and poverty. Hence, Indian Government's initiative 'Swachh Bharat Abhiyan' (Clean India Mission) can have profound effect on infectious disease transmission. Operational research and data collection in this 


\section{Epidemiology International Journal}

context will provide insights for planning health strategies.

As shown in (Figure 2), the number of child cases for last many years (post-elimination) has been between 8-10\% [2,3]. This strongly suggests active transmission of the disease going on in the community. So assumptions that we may be just reporting backlog cases will be misleading.
This emphasizes need of early diagnosis and proactive case finding. One may find statistically significant drop in percentage of child cases $(\mathrm{p}<0.05)$ amongst newly diagnosed cases both in India and globally in last five years. This may give us a hope. But continued occurrence of new child cases is an indication that there is active transmission going on and interrupting such transmission is essential.
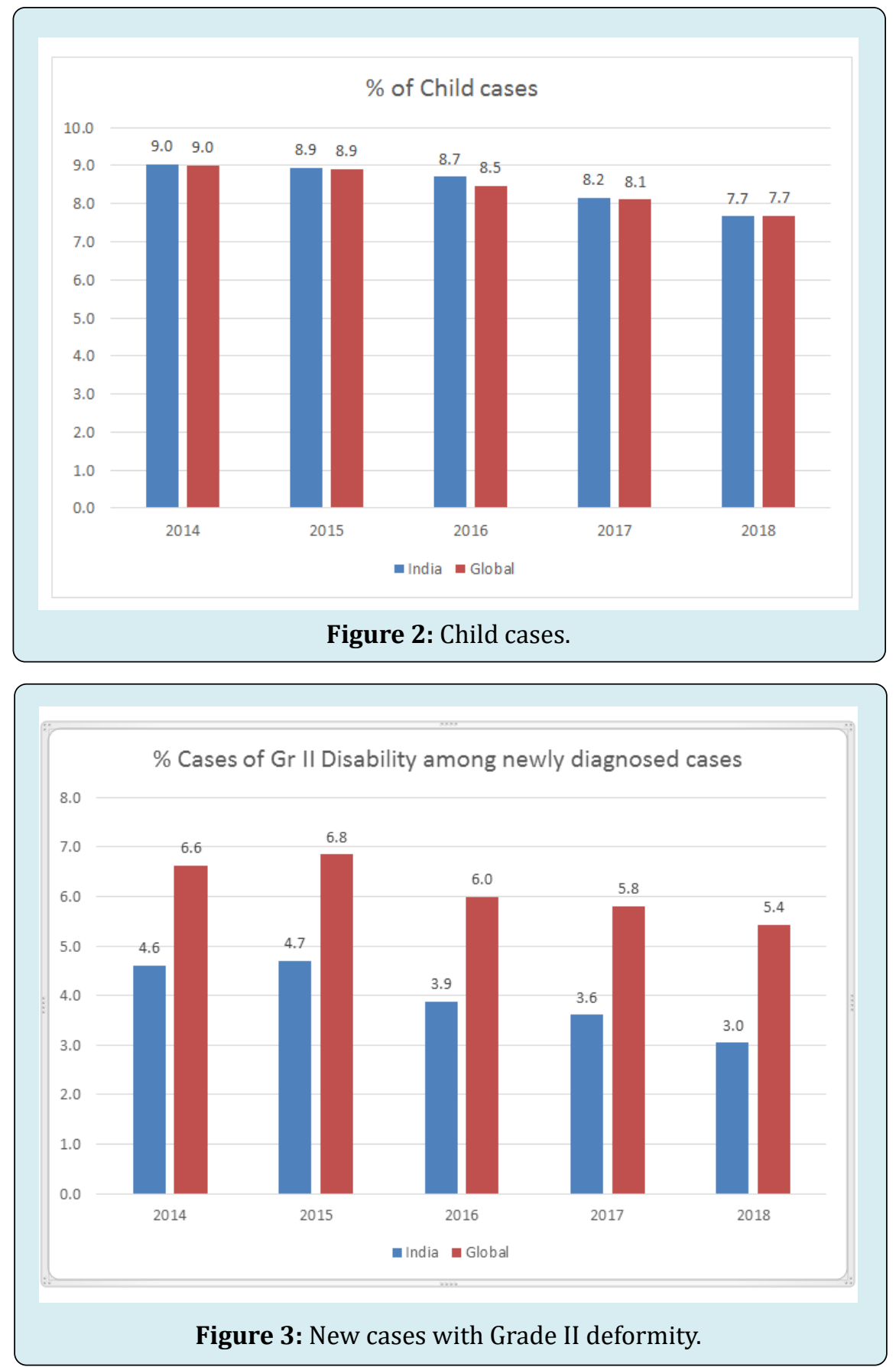

Though clinical picture of the disease with reference to visible deformities may have changed, but the Grade II disability is reported in newly diagnosed patients. Data from last five years again show some decline in percent of new 


\section{Epidemiology International Journal}

cases with Grade II disability (Figure 3). But then it raises the question that the newly diagnosed cases are indicators of genuinely new and are resulted from ongoing transmission. It is needless to say that the stigma associated with the disease is due to deformities and a lot more is desired to be done in this area. Nerve function impairment due to nerve damage during the course of the disease (immunological reactions) result in deformities and hence finding markers for early detection of nerve function impairment or patients as risk to develop reaction is essential $[16,17]$. Studies carried out in other inflammatory diseases can provide clues for parallel studies in leprosy.

Multi drug therapy has been very effective in the treatment of leprosy and success of disease elimination can be attributed to it. But in 2018 a total of 3363 relapse cases were reported globally [3]. Maximum cases were from Brazil (1840) followed by India (436) and Indonesia (284). It is important to identify such cases and differentiate them from late immunological reactions and reinfection. Such cases are also important for studying secondary drug resistance.

Some isolated reports on drug resistance and recent more organized data on global surveillance on drug resistance in relapse cases has raised concerns. Prospective open survey conducted by WHO surveillance network for the period 200915 showed 58 out of 1143 relapse cases $(5.1 \%)$ and 16 out of 789 new cases (2\%) showed rifampicin resistance [18]. What appears as a secondary drug resistance in relapse cases may turn into primary drug resistance in new cases which will then severely impact the disease control Programme. Hence, monitoring drug resistance and simultaneously developing new alternative drugs has become the need of the hour. 'Global leprosy strategy 2016-2020' launched by WHO in April 2016 focuses towards a leprosy free world [19] but we are yet to understand the disease fully.

\section{Conclusion}

It may appear that we have covered a large ground and it is just a last mile to go to reach zero leprosy status. This can bring complacency which will be very dangerous at this stage when we actually require better diagnostic tools for early case detection, improved clinical management that will help in prevention of nerve function impairment and alternative medicines to tackle drug resistance and non-responding reaction cases. Leprosy status is hanging between stages of elimination of disease and elimination of infection. This trend need to move forward towards eradication and not backward. Maintaining status quo will not help.

\section{References}

1. Dowdle WR (1999) The Principles of Disease Elimination and Eradication. MWWR 48(1): 23-27.

2. (2005) Weekly Epidemiological Record. World Health Organization 80(34): 289-296.

3. (2019) Weekly Epidemiological Record. World Health Organization 94(35/36): 389-412.

4. NLEP Annual Reports 2009-10, 2010-11, 2011-12, 2012-2013, 2013-2014, 2014-2015, 2015-2016. Central Leprosy Division, Directorate General of Health Services, Ministry of Health and Family Welfare, Government of India, Nirman Bhavan, New Delhi.

5. Bakker MI, Hatta M, Kwenang A, Faber WR, van Beers SM, et al. (2004) Population survey to determine risk factors for Mycobacterium leprae transmission and infection. Int J Epidemiol 33(6): 1329-1336.

6. Smith WC, Smith CM, Cree IA, Jadhav RS, Macdonald $M$, et al. (2004) An approach to understanding the transmission of Mycobacterium leprae using molecular and immunological methods: results from the MILEP2 study. Int J Lepr Other Mycobact Dis 72(3): 269-277.

7. Lavania M, Turankar RP, Karri S, Chaitanya VS, Sengupta $U$, et al. (2013) Cohort study of the seasonal effect on nasal carriage and the presence of Mycobacterium leprae in an endemic area in the general population. Clin Microbiol Infect 19(10): 970-974.

8. Balamayooran G, Pena M, Sharma R, Truman RW (2015) The armadillo as an animal model and reservoir host for Mycobacterium leprae. Clin Dermatol 33(1): 108-115.

9. Turankar RP, Lavania M, Singh M, Siva Sai KS, Jadhav RS (2012) Dynamics of Mycobacterium leprae transmission in environmental context: deciphering the role of environment as a potential reservoir. Infect Genet Evol 12(1): 121-126.

10. Lavania M, Katoch K, Katoch VM, Gupta AK, Chauhan DS, et al. (2008) Detection of viable Mycobacterium leprae in soil samples: insights into possible sources of transmission of leprosy. Infect Genet Evol 8(5): 627-631.

11. Lahiri R, Krahenbuhl JL (2008) The role of free-living pathogenic amoeba in the transmission of leprosy: a proof of principle. Lepr Rev 79(4): 401-409.

12. Wheat WH, Casali AL, Thomas V, Spencer JS, Lahiri $\mathrm{R}$, et al. (2014) Long-term survival and virulence of Mycobacterium leprae in amoebal cysts. PLoS Negl Trop Dis 8(12): 3405 .

13. Turankar RP, Lavania M, Darlong J, Siva Sai KSR, Sengupta U, et al. (2019) Survival of Mycobacterium leprae and 


\section{Epidemiology International Journal}

association with Acanthamoeba from environmental samples in the inhabitant areas of active leprosy cases: A cross sectional study from endemic pockets of Purulia, West Bengal. Infect Genet Evol 72: 199-204.

14. Turankar RP, Lavania M, Chaitanya VS, Sengupta U, Darlong J, et al. (2014) Single nucleotide polymorphismbased molecular typing of $\mathrm{M}$. leprae from multicase families of leprosy patients and their surroundings to understand the transmission of leprosy. Clin Microbiol Infect 20(3): 0142-0149.

15. Lavania M, Jadhav R, Turankar RP, Singh I, Nigam A, et al. (2015) Genotyping of Mycobacterium leprae strains from a region og high endemic leprosy prevalence in India. Infect Genet Evol 36: 256-261.

16. Chaitanya VS, Lavania M, Nigam A, Turankar RP, Singh I, et al. (2013) Cortisol and proinflammatory cytokine profile in type 1 (reversal) reactions of leprosy. Immunol Lett 156(1-2): 159-167.

17. Chaitanya VS, Jadhav RS, Turankar RP, Lavania M, Singh $M$, et al. (2015) Interleukin-17F single nucleotide polymorphism $(7488 \mathrm{~T}>\mathrm{C})$ and its association with susceptibility to leprosy. Int J Immunogenet 41(2): 131137.

18. Cambau E, Saunderson P, Matsuoka M, Cole ST, Kai M, et al. (2018) Antimicrobial resistance in leprosy: results of the first prospective open survey conducted by a WHO surveillance network for the period 2009-15. Clin Microbiol Infect 24(12): 1305-1310.

19. (2016) Global leprosy strategy 2016-2020: Accelerating towards a leprosy-free world. New Delhi, World Health Organization. 